\title{
Chapter 27 \\ De-extinction and Gene Drives: The Engineering of Anthropocene Organisms
}

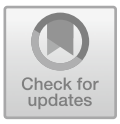

\author{
Christopher J. Preston
}

\begin{abstract}
Advances in gene reading, gene synthesis, and genome editing are making possible a number of radical new practices for transforming animal futures in the Anthropocene. De-extinction may make it possible to bring back lost species. Gene drives may enable the sending of desirable traits through wild populations of organisms. The hype accompanying these promises can make each of them look ethically irresistible. This chapter investigates the 'speculative ethics' that has arisen around these technologies, asking questions about both their viability and the approach to animals they contain. Reductive and non-relational thinking is identified as one potential problem with the thinking behind these techniques. The neglect of non-human agency is identified as another. After indicating some of the problems these two ways of conceptualizing an animal and its genome can create, a brief suggestion is made about how to better conceptualize animal futures in the Anthropocene.
\end{abstract}

\subsection{Synthetic Animal Futures}

From the perspective of evolutionary biology, we live in radical times. Since the conclusion of the Human Genome Project in 2003, a formidable toolbox has been assembled for reworking the products of Darwinian evolution. The powerful trio of gene sequencing, gene synthesis, and gene editing together appear to make possible the genomic reconstruction of any biological lifeform. Genotypes are becoming moldable in ways that were inconceivable just a few years ago. From Mycoplasma mycoides to Homo sapiens, what you find at the genetic level no longer has to be what you keep.

Research time for this chapter was supported by Critical Scientists Switzerland

\author{
C. J. Preston $(\varangle)$ \\ University of Montana, Missoula, MT, USA \\ e-mail: christopher.preston@mso.umt.edu
}

B. Bovenkerk and J. Keulartz (eds.), Animals in Our Midst: The Challenges

of Co-existing with Animals in the Anthropocene, The International Library of Environmental, Agricultural and Food Ethics 33,

https://doi.org/10.1007/978-3-030-63523-7_27 
Today genomicists don't just sequence genomes, they build them. The turn of the century project known as "Human Genome Read" has given way to "Human Genome Write." The genomes of entirely new organisms are being built from scratch in labs. The genomes of existing ones are being significantly tweaked for traits deemed necessary by human designers. Reductions in costs have outpaced Moore's law (more than halving every two years). The possibilities, say the advocates, are endless. Never before has such a responsibility for the shape of the biological world fallen so completely into one species' hands.

These are head-spinning times for bio-ethicists and particularly challenging times for environmental ethicists. Some of the bedrock positions in the field are being thrown into question. The idea that there is moral significance to longstanding evolutionary processes (Rolston III 1988; Leopold 1949) is having to confront the fact that the independence of these processes from human design is becoming increasingly rare. It is not just that we are in the Anthropocene, the epoch in which unplanned human impacts have undeniably become global. Even more than entering an Anthropocene, the planet is running at some speed towards a biological "synthetic age" (Preston 2018). Thanks to these new tools in biotechnology, unthinkable prospects like the de-extinction of lost species and the re-engineering of wild animal populations are moving towards the realm of possibility. Before long, the ecologies within which our species dwells may be populated by a host of synthetic organisms and carefully re-engineered life forms.

To dismiss these deep technological changes solely on the basis that they replace natural organisms with synthetic ones (Lee 1999) is clearly unacceptable. At a conceptual level, the complexity and ambiguity of a term like 'natural organism' makes such a blanket condemnation philosophically dubious (Siipi 2008; Lie 2016). At a practical level, a position resting on hard-to-defend metaphysical commitments like 'naturalness' looks like a poor basis for policy (Kaebnick 2009). Rhetorically, there is a risk of appearing like a troll or a luddite.

Furthermore, even if there once was an intuitive preference for the natural over synthetic organisms this preference may no longer be determinative. One of the most striking things about these developments in biotechnology from an ethical point of view is how the arguments in favor of deploying them to solve difficult problems in conservation and public health look incredibly compelling. De-extinction, for example, offers the tantalizing promise of returning a number of charismatic and ecologically important animals to the planet's roster of species. Gene drives dangle the carrot of a vast reduction in human suffering in the face of diseases like malaria, dengue fever, and zika. Gene drives are also claimed to offer the possibility of eradicating invasive mammals from island ecosystems without poisons, traps, and the accompanying suffering to animals these methods cause. The moral arguments in favor of the new techniques can look unimpeachable. From a consequentialist standpoint, who would question such desirable outcomes?

What even a cursory inspection reveals, however, is that the promises driving some of these research trajectories rest on what Alfred Nordmann has called in a different technological domain "a speculative ethics" (Nordmann 2007). A speculative ethics is one in which a hypothetical prospect is floated in front of decision-makers and 
their publics in such a way that "an imagined future overwhelms the present" (Nordmann 2007, 32). Speculative thinking expresses confidence that if a certain futuristic research trajectory is followed, then a highly desirable result will follow. "What looks like an improbable, merely possible future in the first half of the [if-then] sentence, appears in the second half as something inevitable" (ibid.).

In the case of animals, a speculative biotechnological ethics appears to be creating a misleading mandate for humans to reconstruct the life forms that surround them. In the following pages, I show how the discourse around both de-extinction and gene drives is creating a harmful speculative ethics of animal biotechnology. I put part of the blame for this harmful direction on two types of faulty thinking. One is the methodological problem of non-relational and reductive thinking. The other is the ethical problem of the neglect of non-human agency. In identifying this second fault, I float the possibility of expanding the idea of agency in organisms to include the agency of the genome. I conclude by pointing briefly to a couple of the costs of this inappropriately speculative ethics in two arenas in which its applications are most often touted.

\subsection{Speculations About de-Extinction}

De-extinction demands the careful application of all three of the powerful tools gilding today's biotechnology toolbox. In order to de-extinct a lost species, a researcher would need an accurate account of the genome of the absent organism. The sequencing techniques perfected during the Human Genome Project, pioneered by Craig Venter's 'shotgun approach,' have pushed the door open to this possibility (Venter et al. 1998).

In many cases, sequencing requires analysis of actual tissue from an extinct animal. Sometimes this is surprisingly easy to find. Wooly mammoth tusks, bones, hair, and even whole flanks of their frozen flesh have been dug up in various locations across northern Europe and the Arctic. Numerous passenger pigeon specimens exist in U.S. natural history museums. Stellar sea cow bones are regularly being freed from sea ice to wash up on northern shores. Thirteen different thylacine fetuses (known as 'joeys') sit preserved in bottles of ethanol in zoos and museums in Hobart, Melbourne, Sydney, and Prague. ${ }^{1}$ As a result of these existing DNA fragments, wooly mammoth, passenger pigeon, and thylacine genomes have all already been sequenced.

Once an accurate read of the genome is available, this read can be compared to the genome of a closely related species. A wooly mammoth, for example, can be compared to an Asian elephant, a Pyrenean ibex to a domestic goat, a passenger pigeon to a band-tailed pigeon. In many of these cases, the gene sequences will have an overlap in the high ninety percent range. An Asian elephant, for example,

\footnotetext{
${ }^{1}$ In future the task of gathering threatened or extinct animal DNA may be much easier. A number of "Frozen Zoos" have been set up to deliberately preserve cellular tissues so DNA is available for future research needs.
} 
is already $99.96 \%$ wooly mammoth (Revive \& Restore 2018). This considerable overlap, however, does not make things altogether easy. In mammoths, even this small difference amounts to approximately 1.4 million different nucleotides (Shapiro 2017). But when the main genetic differences between the living and the extinct species have been identified, gene synthesis and gene editing come into play.

Gene synthesis techniques allow genes and genome sequences to be engineered in a laboratory out of their constituent chemicals (a nucleobase, phosphate, and sugar). Although the history of gene synthesis dates back to 1955 and the work of Sir Alexander Todd, it is only recently that computerized sequencing tools and plunging costs have turned a technique that earned its creators Nobel Prizes into a something you can practice in your garage. Synthetically made nucleotides have already been stitched together to form a whole bacterial genome with more than a million base pairs (Gibson et al. 2010) and the construction of the much larger genome of the first eukaryote is in process (Richardson et al. 2017). With typical animal genes possessing anything from a few hundred to a couple of million bases, the individual genes responsible for the defining characteristics of an extinct animal are within the grasp of today's gene synthesis experts.

With the critical genes synthesized, the third technique required for de-extinction is a reliable gene editing mechanism that can be used to transform the genome of the living species into something that resembles the genome of the extinct species. Since 2012, the CRISPR Cas9 editing system has been available to cut living genomes at precisely targeted places. The editing system uses RNA guide molecules to identify the spot and a 'CRISPR package' can remove the targeted genes from the genome and insert new, extinct-animal-genes in their place. A Harvard lab run by George Church has already used these techniques to insert several of the genes that create characteristic wooly mammoth traits-hairiness, cold resistance, and copious quantities of subcutaneous fat-into an Asian elephant genome (Lewis 2015). ${ }^{2}$

At a future time, improved versions of these techniques might allow de-extinct animal embryos to be created by combining gene synthesis and gene editing with somatic cell nuclear transfer, stem cell embryogenesis, or germ line transmission. Resulting embryos could be implanted into surrogate mothers or placed into artificial wombs for the gestation period. The resulting organisms would be close approximations of extinct animals. These could be hybridized or further edited to become more accurate reproductions. Using Asian elephant eggs, some synthesized genetic material, an accurate gene editing system, and a surrogate mother, these techniques might soon allow a newborn wooly mammoth to roam the earth for the first time in four thousand years (Shapiro 2015).

\footnotetext{
${ }^{2}$ At this stage, none of the editing has resulted in living animals. Rather, the researchers are using Asian elephant tissue cultures sustained in a petri dish to experiment on. These modified cultures have been induced to grow into various tissue types allowing the study of the effects of the gene editing on cell characteristics.
} 


\subsection{Speculations About Gene Drives}

Gene drives use the same sequencing, synthesis, and editing techniques to shape wild populations of fast-breeding sexually-reproducing animals. A significant practical barrier to altering wild populations has always been the inability of a scientist to ever reach all the members of the population she wanted to change. An evolutionary barrier has been the fact that traits chosen by scientists are unlikely to be naturally selected for in wild animals. Evolution, as co-discoverer of DNA Francis Crick pointed out, is much smarter than we are. Even if a deliberately selected trait did, against all odds, turn out to be neutral for an organism, the laws of Mendelian inheritance would ensure the trait is only passed on fifty percent of the time. With these odds it is almost impossible for the inserted gene to become prevalent in a population.

Gene drives work by imitating selfish mechanisms occasionally found in nature which provide genes a better than average chance of being inherited (Burt 2003). A CRISPR Cas9 package can be placed into an organism's germ cells so that a trait selected by the scientist is edited into both chromosomes. When the chromosomes split during meiosis, each chromosome will contain a copy of the selected trait. In this way, after fertilization with the germ cell of the other parent, the zygote is guaranteed to possess the gene in at least one of its chromosomes. Since the editing takes place in the germline the whole editing package is carried into the next generation to perform the same trick again (Esvelt et al. 2014). Recent tests in contained populations of mosquitoes have demonstrated the ability to spread a trait through a population in as few as seven to eleven generations (Kyrou et al. 2018). Such an effective upending of Mendelian rules could theoretically allow for the propagation of any chosen genetic construct through a wild population of organisms even though most of the population never set foot anywhere near the lab.

There are a number of reasons why it might be desirable to drive such a change. One of them is to knock down the numbers of a population of a species using what has been called a "suppression drive." A suppression drive could progressively alter the sex ratio of multiple generations of mosquito until the population crashed (Kyrou et al. 2018). Alternatively, a suppression drive could be used to make one sex of a troublesome population sterile (Zhuo et al. 2018). These technique have the potential to reduce - or even eliminate - particular species of mosquitoes that serve as disease vectors (e.g. Aedes aegypti, Aedes gambiae). There is also speculation that similar suppression drives will prove capable of extinguishing populations of invasive rodents from island ecosystems. An organization called Predator Free 2050 together with the New Zealand Department of Conservation are supporting the testing and field assessment of gene drives to eliminate a range of introduced predators from the country within three decades (New Zealand Department of Conservation 2019).

Different forms of gene drive could be inserted with the intention not of suppressing a population but of simply sending a particular non-lethal trait through it. These so-called 'replacement' drives would remake the existing genome sequence of the targeted organism into something that suits a particular human purpose (National Academies of Sciences 2016, 16). Replacement drives could potentially change the 
genotypes of wild animals to prevent them from being disease vectors. They could make an organism susceptible to a particular chemical. More speculatively, they could change an organism's taste for a particular prey or make it smarter at evading predators. Because both suppression and replacement drives would be self-propagating, they would allow the human reach to extend further out from the lab and into the wild than it has ever extended before.

\subsection{The Problem with Promising Big}

In recent years, numerous problems have emerged with the idea of using CRISPR Cas 9 to edit genomes, problems that will plague gene drives, de-extinction, and numerous other gene editing ambitions for public health, conservation, and agriculture. The CRISPR Cas9 gene editing system has been found to sometimes create unpredicted changes both at the cut site and at other parts of the genome far away from where the editing is taking place. Studies have found CRISPR Cas9 causing "large deletions and more complex genomic rearrangements at the targeted sites" as well as completely unintended "lesions distal to the cut site" (Kosicki et al. 2018) (see also Shin et al. 2017; Mou et al. 2017). "We have been lulled into the view that editing is small and local and controllable," says a co-author of one of these studies, "but the reality of DNA repair in a cell is much more complex" (Rusk 2018, 569). ${ }^{3}$

Further problems with CRISPR have been appearing with alarming regularity. The Wall Street Journal reports that gene edits carried out in China to promote muscle growth in pigs resulted in the appearance of extra vertebrae, while similar edits on rabbits created disproportionately large tongues. Goats edited to produce longer wool grew too large during fetal development to undergo natural childbirth (WSJ 2018). When gene drives using the CRISPR Cas9 were inserted into mice by a different research group to see if they could spread a certain coat color, researchers found to their surprise that the drives only worked on female mice. They also found that the DNA break caused by CRISPR was not always repaired correctly, and it affected genomes at a much lower percentage than predicted (Grunwald et al. 2018). Overall, the predictability of the effects of using CRISPR Cas9 appears to be much lower today than researchers originally thought it would be. According to development geneticist Paul Thomas, enthusiasts for CRISPR Cas9 should find all of these results both "sobering" and "a reality check" (Callaway 2018).

To add to the list of complications, CRISPR has also been found to work best when a tumor suppressing protein named p53 is absent (Ihry et al. 2018; Haapaniemi et al. 2018). Having CRISPR work only when p53 is absent is highly inconvenient. The absence of this protein could lead to increased occurrence of cancers in organisms whose genomes are successfully edited, creating a potential problem for the goal of

\footnotetext{
${ }^{3}$ According to one researcher from Imperial College London, these problems are not as widespread in mosquitoes (personal communication, June 2019).
} 
de-extinction (and for a gene drive if it is designed to replace but not eliminate a population).

Even if the technology worked as hoped, the idea that you can remove or replace one gene and then predictably change a phenotype in a replacement drive can also be overstated. Individual genes often work only against a background of other genetic elements, which may be comprised of hundreds of other genes. In many cases, the absence of this background will prevent the change from having the desired effect (Lehner 2013). Many traits are also 'polygenic,' requiring a number of genes to be actualized before the trait is displayed.

Other complications abound. 'Pleiotropic effects' occur when single gene creates more than one unrelated effect. Researchers using CRISPR Cas9 to make an edit to change the pigmentation of a butterfly's wing were surprised to find that the edit changed both the color and the structure of the wing's scales (Matsuoka and Monteiro 2018). Even if a researcher could reach a degree of confidence about the effect of an edit, uncertainty would still be present about the future stability of the edited genome (Shapiro 2017). While it may be possible to swap out a gene under laboratory conditions, it is not known what the consequences of this tinkering may be over the full lifetime of an organism, especially one living not in the controlled conditions of the lab but under the vicissitudes of a wild environment.

In the case of gene drives, the uncertainties are not only about the phenotype produced after using CRISPR Cas9. Above the genetic and organismic level, a great deal remains unclear about how effectively a gene drive would work in the wild. Organisms exist in complex ecological and species relationships. Whether the drive would spread as predicted, whether a natural resistance would evolve, whether hybridization between target and non-target populations might occur, whether horizontal transfer of altered genes to other species might ensue, and whether gene drives could be limited to the environment in which they were designed to operate are all unanswered questions (Biotecknologiradet 2017).

Population dynamics are almost certain to impede how a gene drive works. A study done by the US National Academies of Science expressed caution, concluding that there are "considerable gaps in knowledge regarding the implications of gene drives for an organism's fitness, gene flow in and among populations, and the dispersal of individuals, and how factors such as mating behavior, population sub-structure, and generation time might influence a gene drive's effectiveness" (National Academies of Sciences 2016, 42). Research about how to effect the required molecular changes is where most of the attention has been placed thus far. Far less research has been done on its operation at the population and ecosystem level.

Even before these surprises about CRISPR Cas9 had started to appear, those looking closely at de-extinction were already clued into some of the problems attending the whole idea of recreating lost species. From the very start, a certain amount of doubt had circulated about whether de-extinction was even the right label to use to motivate the research program. In April 2014, a de-extinction task force was created by the International Union for the Conservation of Nature (IUCN) under its Species Survival Commission. The task force examined both the promises and the risks created by thinking about de-extinction for conservation purposes. 
As soon as the task force began its work, it recognized that any 'extinct' species brought back to life through biotechnology would be only an approximation of the species that humans had previously wiped out. The technical difficulties of recreating an exact replica of an extinct species' genome, the effects of missing mitochondrial DNA on fetal development, the lack of the original microbiome of the extinct species, the absence of appropriate ecosystemic conditions, and the lack of an extant animal culture from which a de-extincted individual could learn appropriate behavior meant the organisms recreated would at best be only approximations of the missing animal and not the missing animal itself. As a result, the report decided to characterize the whole endeavor not as an attempt to bring back lost species but as an attempt to create populations of organisms resembling extinct species for the purpose of serving important ecological functions. De-extinction then became "a conservation translocation issue that seeks to re-establish populations of proxy species in suitable areas of habitat to achieve ecosystem conservation benefits" (IUCN/SSC 2016, 5) (emphasis added). To reflect this retreat from the idea of de-extinction, the report was titled 'Guiding Principles on Creating Proxies of Extinct Species for Conservation Benefit.' The report urged readers to be clear on its starting assumption that "none of the current [technological] pathways will result in a faithful replica of any extinct species, due to genetic, epigenetic, behavioural, physiological, and other differences" (IUCN/SSC 2016, 5).

What this quick survey of the problems attending the use of CRISPR Cas9 and the difficulties of recreating extinct organisms reveal is that both gene drives and deextinction remain highly speculative prospects. DNA appears to be neither manipulable enough nor determinative enough to be confident either de-extinction or gene drives can deliver on their promises. Genomes can certainly be edited using CRISPR Cas9 with remarkable accuracy. The resulting organism, however, together with its effect on the population in which it resides, will have a lot about it that we do not know. The lesson, perhaps, is that animals may not be reducible to chemistry of their genomes.

\subsection{Reductionism and Thinking Relationally}

One way to characterize doubts and uncertainties about de-extinction and gene drives revealed above would be to suggest that not enough research has been done and the genetic mechanisms at work are not yet fully understood. The genome is a complicated machine. Perhaps we simply don't yet fully understand it. More work must be needed to iron out the remaining uncertainties.

A slightly different way to characterize the doubts is to suggest the whole picture about the relationship between genes and their expression in an organism is faulty. As the discussion above illustrates, a key part of the problem appears to be the reductive approach to genomes that gene editing and gene synthesis assume. The properties of genetic parts cannot be so easily isolated from the larger contexts in which they operate. Context will determine the appropriateness of connecting a certain genomic 
rearrangement to a predicted behavior. Reducing a genome to its constituent parts may be a useful exercise when trying to draw correlations between individual genes and diseases. Reading a genome can indeed make it possible to offer statistical predictions about the likelihood of certain diseases appearing in individuals. ${ }^{4}$ But it looks like reductionism and non-relational thinking about genomes can be seriously misleading when used as the grounds on which to try de-extincting whole organisms or introducing selected traits across wild populations.

The recent surprises that have emerged around CRISPR gene editing make it clear that the larger genetic, organismic, and ecosystemic contexts in which a single gene operates all affect the phenotype displayed. The broader genetic context can create unexpected deletions attending CRISPR gene edits, both at the targeted editing site and locations on the genome distal to it. The genetic context might mean tumor growth if p53 is absent. It might involve additional unknown effects on the phenotype if the gene is pleiotropic. It might also mean the impotence of the gene drive if resistance to the drive evolves within the genome.

The whole organism context is also relevant. This context might lead to the gene edit not having the desired effect if the typical microbiome, and other epigenetic factors, are not present (Morris 2012). The sex of the organism might impact the effectiveness of the gene drive edit. The stage of development of the organism might also change the likelihood of a gene drive working.

The ecosystemic context can also not be ignored. This context, external to the organism itself, might mean the gene drive not spreading as anticipated if the surrounding population dynamics change. The gene drive might be deployed in an ecosystem that allows it to move into non-target populations of the target species. It might also affect non-target sub-species if the organism with the gene drive hybridizes. Genomic, organismic, and ecosystemic contexts all influence the consequences of a CRISPR gene edit.

The many layers of context that influence how information encoded in a gene gets expressed in a fully-fledged organism make genome editing into a tricky proposition at the best of times. To make matters worse for gene drives and de-extinction, many of these essential contexts are fluid and dynamic. The minute alterations to the organism's genome constantly taking place through mutations as the generations proceed, the organism's constantly shifting microbiome, and the roving populations of surrounding symbionts and competitors are all dynamic factors influencing both genome expression and the genome's prospects in the future. In the case of gene drives, each of these shifting contexts will influence the way the drive spreads-or fails to spread-across the wild world. A non-relational, reductive approach that considers the different chemical structures contained within an organism's genome as interchangeable parts to be engineered at will seems ill-suited for thinking about whole organisms operating in larger ecosystemic contexts.

The multiple contexts influencing the organism point to the importance of thinking about the ontology of a gene in more relational terms. With a relational approach to

\footnotetext{
${ }^{4}$ Several thousand "single gene" diseases have been identified.
} 
ontology, an entity becomes what it is through the relationships in which it participates. In relational worldviews, organisms, processes, or individual genes operate through a multitude of networks, interconnections, and feedback loops. Thinking about them in isolation from their relationships leads to a flawed understanding not only of what they are, but also of how they work.

In a relational approach to genomes, efforts to isolate genetic information and transpose it into completely different genomic, cellular, organismal, and ecological environments will create unpredictable effects. Genes express themselves only through highly specific interactions between various elements found within the many different layers of a given system. Altering the relational context creates different results. This is not simply because the gene now undergoes a different set of interactions. There is a deeper point to be made. When the relational network is changed, so is the gene itself. The gene is constituted by its relations as much as by its chemistry. A subscriber to a relational approach to genes would chuckle at the idea that the chemical components of a living organisms' genome can be edited and exchanged at will with predictable results.

\subsection{Genomes and Non-human Agencies}

If a reductive, non-relational approach to genes is one part of the problem, another part is the neglect of genomic, organismic, and ecosystemic agency. At a very basic level, gene drives and de-extinction are each an attempt to impose human agency onto the world through deliberate changes to an organism's genome. Since genomes are chemical structures made of up nitrogenous bases, phosphates, and sugars, it appears reasonable to suppose it might be possible to excise selected portions of their molecular structure, rebuild others, and swap out undesirable sequences for desirable ones.

The idea of isolating properties of the material world in order to understand how they function before imposing a change upon them is, of course, a central and important part of established scientific and technological practice. In numerous contexts, the approach works. However, in order to ensure that enough predictability and control follow from any imposition of human will, a key assumption must be made. While agency is ascribed to the scientist who is instigating the intervention, it must be assumed the material she is manipulating is in relevant respects passive (or at least passive enough not to thwart the engineer's plans). Once the intervention has occurred, the behavior of the manipulated material must follow linear and known laws. ${ }^{5}$ If predictability is to be possible, any independent agency in the manipulated

\footnotetext{
${ }^{5}$ Engineering does not always require the produced object to exist in stasis. While engineers who create autonomous vehicles do not know everything about the future states and positions of the engineered object, they rely on the belief that the machine they have intentionally designed or modified will behave as they anticipated.
} 
material must fall below a threshold that would allow a future to unfold contrary to the engineer's designs. If it didn't, it would not be engineering but a game of chance.

The idea of using CRISPR Cas9 to engineer biological forms appears to fall short in this regard. There are several different forms of agency that a genetic construct inserted into a genome for gene drives or de-extinction has to encounter. Bacterial agency in the microbiome, the agency of members of the same species in its population, and agency in any symbionts, competitors, or hybrids the organism encounters are all possible disruptors. These dynamic factors influence genome expression as well as the genome's future prospects. Each of these shifting contexts will influence how the gene drive spreads - or fails to spread-across the wild world. For potentially de-extincted animals such as the northern white rhino, the agency within the social and cultural structures leading to the organisms' extinction in the first place remains highly relevant.

In addition to the agency surrounding the altered genome, it is also possible to talk about agency within the genome itself. Although typically thought of as a property of individual organisms and larger collectives, genomes themselves are frequently thought of in agential terms. Dawkins calls them "selfish," Thaler calls them "intelligent," Wills calls them "wise," and Rolston calls them "smart" (Thaler 1994; Wills 1989; Rolston III 2012; Dawkins 2006). While some of these uses are deliberately metaphorical, the problems attending CRISPR Cas9 raise a new set of questions concerning how to think about genetic agency.

It is clear there is spontaneous behavior in the genome that is not the result of linear causes. Before, after, and during both meiosis and mitosis, a range of mutations can occur. The mutations can involve insertions or deletions of genetic material, inversion or translocation of a segment of DNA within a chromosome, duplications of a DNA sequence, changes in individual nucleobases, and other types of unscripted event. In the long run, of course, it is a good thing that these mutations occur. Without them, evolution would never take place. Random changes in the genome are what create the selective advantages (as well as disadvantages) which shape all ecologies.

Mutation can be viewed as a form of spontaneous agency in a genome. Some mutations are caused by external factors or mutagens such as chemicals or radiation. These ones are traceable to external causal factors and are non-agential as far as the genome itself is concerned. Others simply appear during cell division when the chromosomes do not replicate perfectly or when the inherently instability of the bases causes, for example, a cytosine base to become uracil. These latter sorts of changes are entirely spontaneous and unpredictable. They are not traceable to a proximate cause but emerge out of the genome itself. If agency is defined broadly in terms of the capacity for spontaneous and unpredictable action, then mutations will count as a form of agency and this agency clearly belongs to the genome itself.

Even though the notion of genomic agency may be counter-intuitive, the idea of agency existing below the level of the complete organism should not come as a complete surprise. Somewhere between the chemistry of the nucleobases and the complex whole that is the living organism, agency in the more familiar sense emerges. Properties emerging at higher levels can have precursors at lower ones. A variety of forms of agency may be present at levels beneath the whole organism. If random 
mutation is a minimal form of agency, one should perhaps regard the unpredictable insertions and deletions following from CRISPR Cas 9 gene edits as forms of genomic agency. It is certainly clear the genome will not behave as the entirely passive recipient of an inserted gene. The genome responds spontaneously and, in some cases, unpredictably to the new material.

The neglect of agency thus appears alongside non-relational thinking as a second form of faulty philosophy often accompanying the discussion of gene editing for deextinction and for gene drives. The kind of passivity required for precise engineering of organisms in order that they perform designated roles in an environment is simply not there in biology. To think this way incorrectly creates the impression that the research scientist is the only active agent in the gene editing process, while the chemical structures on which she operates are entirely passive. Yet it is clear that the scientist is not the only element of the system whose spontaneous agency influences the outcome. These two forms of faulty thinking are part of the reason why the discussion of gene drives and de-extinction lends itself to a misleading speculative ethics.

\subsection{Speculative Biotechnology and Anthropocene Organisms}

When Alfred Nordmann warned of the dangers of a speculative ethics with powerful emerging technologies, he was concerned about unrealistic projections of what a technology can accomplish having unfortunate consequences. One of the most obvious of these is that a speculative ethics can funnel both funding and enthusiasm towards a research direction that may not in the end deserve it. Over-eager researchers employ a speculative ethics "to invent a mandate for action" (Nordmann 2007, 33). So desirable (and inevitable) does a consequence of a particular technology appear that it becomes morally problematic, and perhaps even inhumane, to even consider not pursuing it. Arguably the current speculations about ending malaria with gene drives or eradicating invasive mammals from island ecosystems fall into this camp. The promise of moral restitution or of huge benefits for conservation by reintroducing de-extincted species (or their proxies) comes not far behind.

Nordmann adds to his argument that speculative ethics can also be damaging because of the opportunity costs it engenders. An over-eager pursuit of speculative silver bullets in the face of complicated environmental and public health challenges creates real dangers. These dangers arise when speculative ethics "squanders the scarce and valuable resource of ethical concern... and deflects consideration from the transformative technologies of the present" (Nordmann 2007, 31).

In cases of public health, there may be less risky interventions with considerable power to curtail the spread of diseases than a speculative gene drive. Without diminishing in any way the substantial challenges still posed by diseases spread through insect vectors, traditional and emerging approaches to control can have promising 
results. ${ }^{6}$ On the island of Zanzibar, symptomatic malaria cases reported at health clinics decreased 94\% from 2003-2015 (Björkman et al. 2019). India has reduced its malaria deaths by two thirds since 2000 with a $24 \%$ drop in cases between 2016 and 2017 (World Health Organization 2018). The Indian government maintains its goal of complete malaria eradication by 2030 .

While these numbers in no way suggest that malaria is not still a significant and tragic public health issue, they might provide a reason to pause before the premature embrace of a highly speculative technology such as a gene drive. In situations where the traditional methods involve dramatic improvements in public health facilities, education, and funding, there might also be a broad range of co-benefits to pursuing the technologically less flashy solution over the more risky, speculative one.

Similarly in cases of conservation, devoting resources to the proximate causes of a species becoming endangered or extinct may be more beneficial in the end than devoting resources to a technologically speculative one. Even if there is no reason to believe it is a zero sum game, strategies such as the protection of good habitat, the provision of economic security for local populations, and improved attention to the international forces contributing to the original extinction threat may provide more lasting benefits than spending considerable amounts of money attempting to recreate an extinct animal through a speculative technology. Without the needed social, economic, and cultural changes, the de-extincted animal is unlikely to face any better a fate than its predecessors. Furthermore, implementing these traditional strategies will usually provide benefits for other organisms who share the habitat of the endangered or extinct one. In each of these cases, the speculative ethics may be creating the distraction Nordmann warns about.

Synthetic biology - the discipline within which gene reading, gene synthesis, and gene editing operate-is often characterized as "an engineer's approach to biology" (Breithaupt 2006). De-extinction and gene drives look very much like the transference of the techniques of mechanical engineering from physics over into to biology. If developed successfully, their proponents argue, they will not only solve some major public health and conservation problems, they might also remove some of the mystery that surrounds the concept of life by reducing it to its constituent parts. For some, these developments are both inevitable and desirable. Yuval Harari describes gene editing as playing a key role in the next revolution in human history, one in which "intelligent design becomes the basic principle of life" (Harari 2015, timeline).

The breakthroughs that have taken place in gene reading, synthesis, and editing in the last decade and a half certainly represent a remarkable scientific achievement. A great deal of good is likely to come from their careful application in appropriate domains. The moral benefit of solving some of the problems they seek to address would undoubtedly be high. What recent findings about gene editing reveal,

${ }^{6}$ Climate change may intensify these challenges. 
however, is that approaching the genome with an engineer's mentality has a number of shortcomings.

When it comes to building or amending whole organisms, treating life as modular at the genetic level may in the end prove to be highly misguided. Organisms have always existed in highly complex genomic and ecological contexts that present significant barriers to the engineering approach. Plants and animals are bound up in multiple layers of constitutive relationships. Their lives are also entangled with multiple forms of agency that lend them their shape. At a time when new research paradigms such as multi-species studies are starting to highlight the significance of these relationships and agencies (Haraway 2016; Tsing 2015; Van Dooren 2016), attempts to engineer biology with gene synthesis and gene editing risk neglecting these provocative new insights. A speculative ethics of biotechnology consistently risks steering the conversation about de-extinction and gene drives away from contemporary understandings about the embeddedness of all animals in multiple human and non-human contexts. This non-relational thinking has certainly pushed the conversation about these new techniques far ahead of where it currently deserves to be.

The presence of lively, spontaneous animals with whom our species shares this planet has provided mystery, challenge, and inspiration throughout the two and a half million year history of our kind. In an increasingly crowded Anthropocene world, the presence of independent animals will provide a vital counterpoint to a harmful 'species narcissism' as ever more of the earth's surface becomes stamped by human designs (Mark 2015). Some forms of biotechnology appear to express this narcissism by being blind to the relationships and agencies of the animal others with whom all of our lives are entwined.

The linking of biology with engineering is symptomatic of this attitude. This linking may not simply be a rhetorical mistake. As National Medal of Science and Crafoord Prize winner Carl Woese suggested, "a society that permits biology to become an engineering discipline, that allows science to slip into the role of changing the living world without trying to understand it, is a danger to itself" (Woese 2004, 173).

\section{References}

Biotecknologiradet. 2017. Statement on gene drives. The Norwegian Biotechnology Advisory Board. Oslo. http://www.bioteknologiradet.no/filarkiv/2017/02/Statement-on-gene-drives.pdf.

Björkman, A., D. Shakely, A.S. Ali, U. Morris, H. Mkali, A.K. Abbas, et al. 2019. From high to low malaria transmission in Zanzibar-Challenges and opportunities to achieve elimination. BMC Medicine 17 (1): 14. https://doi.org/10.1186/s12916-018-1243-z.

Breithaupt, H. 2006. The engineer's approach to biology. EMBO Reports 7 (1): 21-23.

Burt, A. 2003. Site-specific selfish genes as tools for the control and genetic engineering of natural populations. Proceedings of the Royal Society of London. Series B: Biological Sciences 270 (1518): 921-928. https://doi.org/10.1098/rspb.2002.2319.

Callaway, E. 2018. Controversial CRISPR "gene drives" tested in mammals for the first time. Nature, July 10. https://www.scientificamerican.com/article/controversial-crispr-gene-drives-tested-inm ammals-for-the-first-time/. 
Dawkins, R. 2006. The selfish gene, 30th Anniversary Edition. New York: Oxford University Press.

Esvelt, K.M., A.L. Smidler, F. Catteruccia, and G.M. Church. 2014. Concerning RNA-guided gene drives for the alteration of wild populations. eLife 3: e03401. https://doi.org/10.7554/eLife.03401.

Gibson, D.G., J.I. Glass, C. Lartigue, V.N. Noskov, R.-Y. Chuang, M.A. Algire, et al. 2010. Creation of a bacterial cell controlled by a chemically synthesized genome. Science 329 (5987): 52-56. https://doi.org/10.1126/science.1190719.

Grunwald, H.A., V.M. Gantz, G. Poplawski, X.S. Xu, E. Bier, and K.L. Cooper. 2018. SuperMendelian inheritance mediated by CRISPR/Cas9 in the female mouse germline. Nature 566 (7742): 105-109. https://doi.org/10.1101/362558.

Haapaniemi, E., S. Botla, J. Persson, B. Schmierer, and J. Taipale. 2018. CRISPR-Cas9 genome editing induces a P53-mediated DNA damage response. Nature Medicine 24 (7): 927-930. https:// doi.org/10.1038/s41591-018-0049-z.

Harari, Y.N. 2015. Sapiens: A brief history of humankind, 1st ed. New York: HarperCollins.

Haraway, D.J. 2016. Staying with the trouble: Making kin in the Chthulucene. Durham, NC: Duke University Press.

Ihry, R.J., K.A. Worringer, M.R. Salick, E. Frias, D. Ho, K. Theriault, et al. 2018. P53 inhibits CRISPR-Cas9 engineering in human pluripotent stem cells. Nature Medicine 24 (7): 939-946. https://doi.org/10.1038/s41591-018-0050-6.

IUCN/SSC. 2016. Guiding principles on de-Extinction for conservation benefit (Version 1.0). Gland, Switzerland.

Kaebnick, G.E. 2009. Should moral objections to synthetic biology affect public policy? Nature Biotechnology 27 (12): 1106-1108. https://doi.org/10.1038/nbt1209-1106.

Kosicki, M., K. Tomberg, and A. Bradley. 2018. Repair of double-strand breaks induced by CRISPRCas9 leads to large deletions and complex rearrangements. Nature Biotechnology 36: 765-771. https://doi.org/10.1038/nbt.4192.

Kyrou, K., A.M. Hammond, R. Galizi, N. Kranjc, A. Burt, A.K. Beaghton, et al. 2018. A CRISPRCas9 gene drive targeting doublesex causes complete population suppression in caged Anopheles gambiae Mosquitoes. Nature Biotechnology 36 (11): 1062-1066. https://doi.org/10.1038/nbt. 4245.

Lee, K. 1999. The natural and the artefactual: The implications of deep science and deep technology for environmental philosophy. Lanham, MD: Lexington Books.

Lehner, B. 2013. Genotype to phenotype: Lessons from model organisms for human genetics. Nature Reviews Genetics 14 (3): 168-178. https://doi.org/10.1038/nrg3404.

Leopold, A. 1949. A sand county almanac. New York: Oxford University Press.

Lewis, T. 2015. Wooly Mammoth genes inserted into Elephant cells. LiveScience, March 26. https:// www.livescience.com/50275-bringing-back-woolly-mammoth-dna.html.

Lie, S.A.N. 2016. Philosophy of nature: Rethinking naturalness. Abingdon, UK: Taylor and Francis. https://www.routledge.com/Philosophy-of-Nature-Rethinking-naturalness-1st-Edition/ Lie/p/book/9781138792883.

Mark, J. 2015. Satellites in the high country: Searching for the wild in the age of man. Washington, DC: Island Press.

Matsuoka, Y., and A. Monteiro. 2018. Melanin pathway genes regulate color and morphology of butterfly wing scales. Cell Reports 24 (1): 56-65. https://doi.org/10.1016/j.celrep.2018.05.092.

Morris, K.V. (ed.). 2012. Non-coding RNAs and epigenetic regulation of gene expression: Drivers of natural selection. Poole, UK: Caister Academic Press.

Mou, H., J.L. Smith, L. Peng, H. Yin, J. Moore, X. Zhang, et al. 2017. CRISPR/Cas9-mediated genome editing induces exon skipping by alternative splicing or exon deletion. Genome Biology 18 (1): 108. https://doi.org/10.1186/s13059-017-1237-8.

National Academies of Sciences, Engineering, and Medicine. 2016. Gene drives on the horizon. Washington, DC: National Academies Press. https://doi.org/10.17226/23405.

New Zealand Department of Conservation. 2019. Strategic Priorities. https://www.doc.govt.nz/ about-us/statutory-and-advisory-bodies/nz-conservation-authority/strategic-priorities/. 
Nordmann, A. 2007. If and then: A critique of speculative nanoethics. NanoEthics 1 (1): 31-46. https://doi.org/10.1007/s11569-007-0007-6.

Preston, C.J. 2018. The synthetic age: Outdesigning evolution, resurrecting species, and reengineering our world. https://mitpress.mit.edu/books/synthetic-age.

Revive \& Restore. 2018. Wooly Mammoth project: Progress to date. https://reviverestore.org/pro jects/woolly-mammoth/progress-to-date/.

Richardson, S.M., L.A. Mitchell, G. Stracquadanio, K. Yang, J.S. Dymond, J.E. DiCarlo, et al. 2017. Design of a synthetic yeast genome. Science 355 (6329): 1040-1044. https://doi.org/10. 1126/science.aaf4557.

Rolston III, H. 1988. Environmentale ethics: Duties to and values in the natural world. Philadelphia, MA: Temple University Press.

Rolston III, H. 2012. A new environmental ethics: The next millenium for life on earth, 1 st ed. New York: Routledge.

Rusk, N. 2018. Surprising CRISPR roadblocks. Nature Methods 15 (8): 569. https://doi.org/10. 1038/s41592-018-0097-9.

Shapiro, B. 2017. Pathways to de-extinction: How close can we get to resurrection of an extinct species? Functional Ecology 31 (5): 996-1002. https://doi.org/10.1111/1365-2435.12705.

Shapiro, B. 2015. How to clone a Mammoth: The science of de-extinction, 1st ed. Princeton, NJ: Princeton University Press.

Shin, H.Y., C. Wang, H.K. Lee, K.H. Yoo, X. Zeng, T. Kuhns, et al. 2017. CRISPR/Cas9 targeting events cause complex deletions and insertions at 17 sites in the mouse genome. Nature Communications 8: 15464. https://doi.org/10.1038/ncomms15464.

Siipi, H. 2008. Dimensions of naturalness. Ethics and the Environment 13 (1): 71-103.

Thaler, D.S. 1994. The evolution of genetic intelligence. Science 264 (5156): 224-225. https://doi. org/10.1126/science.8146652.

Tsing, A.L. 2015. The mushroom at the end of the world: On the possibility of life in capitalist ruins. Princeton, NJ: Princeton University Press.

Van Dooren, T. 2016. Flight ways: Life and loss at the edge of extinction. New York: Columbia University Press.

Venter, J.C., M. Adams, G.G. Sutton, A.R. Kerlavage, H.O. Smith, M. Hunkapiller, et al. 1998. Shotgun sequencing of the human genome. Science 280 (5369): 1540-1542. https://doi.org/10. 1126/science.280.5369.1540.

Wills, C. 1989. The wisdom of the genes: New pathways in evolution. New York: Basic Books.

Woese, C.R. 2004. A new biology for a new century. Microbiology and Molecular Biology Reviews 68 (2): 173-186. https://doi.org/10.1128/MMBR.68.2.173-186.2004.

World Health Organization. n.d. World malaria report 2018. Accessed March 7, 2019. www.who. int/malaria.

Zhuo, J.-C., Q.-L. Hu, H.-H. Zhang, M.-Q. Zhang, S.B. Jo, and C.-X. Zhang. 2018. Identification and functional analysis of the doublesex gene in the sexual development of a hemimetabolous insect, the Brown Planthopper. Insect Biochemistry and Molecular Biology 102: 31-42. https:// doi.org/10.1016/j.ibmb.2018.09.007. 
Open Access This chapter is licensed under the terms of the Creative Commons Attribution 4.0 International License (http://creativecommons.org/licenses/by/4.0/), which permits use, sharing, adaptation, distribution and reproduction in any medium or format, as long as you give appropriate credit to the original author(s) and the source, provide a link to the Creative Commons license and indicate if changes were made.

The images or other third party material in this chapter are included in the chapter's Creative Commons license, unless indicated otherwise in a credit line to the material. If material is not included in the chapter's Creative Commons license and your intended use is not permitted by statutory regulation or exceeds the permitted use, you will need to obtain permission directly from the copyright holder.

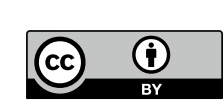

